\title{
Prevalence of HIV-1 Drug Resistance, Distribution of Subtypes and Drug resistance-associated mutations among Treatment-experienced Individuals in Chengdu, Southwest China, 2014- 2016
}

Jiayi Chen

Sichuan University

Yang Liu

Chengdu Center for Disease Control and Prevention

Sijing Liu

Sichuan University

Dan Yuan

Sichuan Center for Disease Control and Prevention

Ling Su

Sichuan Center for Disease Control and Prevention

Li Ye

Sichuan Center for Disease Control and Prevention

Fanghong Gong

Chengdu Center for Disease Control and Prevention

Yushuang Gao

Chengdu Center for Disease Control and Prevention

Saira Baloch

Sichuan University

Xiaofang Pei ( $\nabla$ xfpeiscu@163.com )

Sichuan University

Research article

Keywords: HIV-1, Drug resistance, Subtypes, Drug resistance-associated mutations

Posted Date: December 31st, 2019

DOI: https://doi.org/10.21203/rs.2.16258/v2 
License: (c) (i) This work is licensed under a Creative Commons Attribution 4.0 International License. Read Full License 
The authors have withdrawn this preprint from Research Square 